\title{
Assessment of the Impact of Severe Early Childhood Caries on the Quality of Life of Preschool Children and their Parents
}

\author{
Maria Mtalsi ${ }^{1}$ Khadija Oumensour ${ }^{1}$ Amal Chlyah' ${ }^{1}$ ineb Aljalil' ${ }^{1}$ Meryem Choukir ${ }^{2}$ \\ Sara Agoujjim² Samira El Arabi'
}

'Department of Pediatric Dentistry, Faculty of Dental Medicine,

Address for correspondence: Khadija Oumensour, Department of University Hassan II, Casablanca, Morocco

${ }^{2}$ Private Practice, Casablanca, Morocco

\author{
Pediatric Dentistry, Faculty of Dental Medicine, University Hassan II, \\ Rue Abou Alaa Zahr, Casablanca 21100, Morocco \\ E-mail: dr.oumensour@hotmail.com
}

\begin{abstract}
Objective: The aim of the present study was to assess the prevalence of the early childhood caries (S-ECC) and its impact on preschool children's life (aged 4-6), as well as on their parents, in one of the most popular prefectures in Casablanca, Morocco.

Materials and Methods: Parents of 546 children attending 11 randomly selected preschools ( 7 private and 4 public institutions) were invited to complete 13 items of an oral health questionnaire and had their children undergo a dental examination. The quality of life was evaluated using the Early Childhood Oral Health Impact Scale (ECOHIS).

Statistical analysis: The data collected were analyzed using the SPSS (Statistical Package for the Social Sciences). To find the comparison between groups, Chi-square test was used.

Results: The prevalence of the ECC and the S-ECC were $74.2 \%$ and $47.3 \%$ respectively. The negative effect of S-ECC on children's quality of life has many aspects: $59.3 \%$ of them have experienced tooth pain, $41.5 \%$ have reported eating difficulties, and $41.3 \%$ have had drinking difficulties. Moreover, $40 \%$ of parents expressed feelings of guilt and $10.6 \%$ had to take time off work due to their children's oral health status. On another note, the financial impact of the S-ECC was also significant.

Conclusion: The S-ECC negatively impacts the life quality of children aged between 4 and 6 years old in addition to their parents'. This suggests a need for further strategic planning and preventive program adapted to such a public health problem.
\end{abstract}

Keywords: Early childhood caries, ECOHIS, oral health, public health, quality of life, severe early childhood caries

\section{Introduction}

The American Academy of Pediatric Dentistry has defined the Early Childhood Caries (ECC) as the presence of one or more decayed (non-cavitated or cavitated lesions), missing (due to caries), or filled tooth surfaces in any primary tooth in a preschool-age child between birth and 71 months of age. According to the same academy, the severe early childhood caries (S-ECC) refers to a DMFT score higher than 4 at age 3 , higher than 5 at age 4, or higher than 6 at age 5.[1]

The prevalence of ECC is influenced by many factors and can vary from one study to another. It can exceed $85 \%$ in some populations, especially in underde-

How to cite this article: Mtalsi M, Oumensour K, Chlyah A, Aljalil Z, Choukir M, Agoujjim S, El Arabi S. Assessment of the Impact of Severe Early Childhood Caries on the Quality of Life of Preschool Children and their Parents. J Pediatr Dent 2020;6(1):20-25 
veloped countries,[1] and leads consequently to a significant public health problem.

The ECC is the sum of several risk factors' interaction, such as mother to child streptococcus early contamination, mother's education level, night-time bottle feeding, sugar consumption between meals, lack of toothbrushing, and the use of fluoride toothpaste, socioeconomic status, as well as other factors.[2-4]

In addition to its short-term consequences (pain, systemic infection, and abscess), many studies have shown that the ECC affects the child's development and growth due to difficulties related to feeding and sleeping, to aesthetic appearance, and social integration.[5]

In order to assess the impact of ECC on the children's quality of life, several instruments have been developed in the last couple of years. One of these instruments is the early childhood oral health impact scale: the ECOHIS, which is a specific instrument that has been translated into different languages, including Arabic, and has been validated in many countries.[6]

The present study aims to identify the prevalence of ECC and S-ECC, as well and their impact on the quality of life among pre-school children and their parents in an underprivileged prefecture of Casablanca, Morocco.

\section{Materials and Methods}

\section{Study population and data collection}

A cross-sectional oral health survey was undertaken by the parents of preschool children, aged between 4 and 6 years old, in a prefecture of Casablanca, Morocco. Based on the registered preschools (2016-2017), there were 20 governmental institutions ( 882 children) and 32 private institutions (2391 children), with an enrolled population of approximately 3273 children.

In order to determine the study sample, a cluster sampling has been selected. A total of 11 preschools were selected by a systematic random sampling from the school lists: 7 governmental preschools and 4 private preschools with 380 children. To be included in the study, children must meet all the inclusion criteria: aged between 4 to 6 years of age, both genders, without systematic diseases, without physical or learning disabilities, under no form of orthodontic treatment, and only after parental consent. The investigation was conducted using a questionnaire and accompanied by an oral examination. Before starting the survey, written authorizations and written consents were obtained from participating parents.

\section{Assessment of the socio-demographic status}

Data collection has been performed by a questionnaire, completed by participating parents. The questionnaire reported the child's age and gender, the mother's age, her education level, and socio-economic status as established by the WHO.

\section{Assessment of dietary habits and oral hygiene practices}

11 variables were evaluated in this section, such us feeding demand (breastfeeding/bottle feeding), night-time feeding (breastfeeding/bottle feeding), sugar consumption between meals, bread sucking or similar habits, toothbrushing, first time toothbrushing, tooth brushing techniques, usage of fluoride toothpaste, dental checkup and passive smoking.

\section{Assessment of oral health}

The dental examinations were conducted by the same practitioner in classrooms using natural light. The cotton roll was used to remove plaque and food debris that obstructed inspection on tooth surfaces, to confirm the presence of a carious cavity when necessary. Teeth were examined visually and using a sterile mouth mirror and two probes. ECC was assessed according to the WHO criteria (DMFT).

The diagnosis of ECC was made in the presence of at least one decayed, missing, or filled tooth surface caused by caries. The S-ECC was considered if the DMFT score was higher than 5 at the age of 4 years and higher than 6 at age of 5 years.

\section{Early childhood oral health impact scale}

The child and his/her family's quality of life were assessed using the ECOHIS questionnaire in its Moroccan and French versions. The questionnaire consists of 13 items grouped into two main parts.

The first section focuses on the "Impact On The Child", which includes 4 areas: symptoms (tooth pain), function (drinking difficulty, eating difficulty, the difficulty encountered in pronouncing, scholar absenteeism), psychology ( sleep disorder, irritability, and frustration), self-image (smiling difficulty, speaking difficulty). The second section examined three areas related to the parents: distress (perturbation and guilt), function (taken time off work), and the financial impact.

A scale from 0 to 5 points was available for each response $(0=$ never, $1=$ hardly ever, $2=$ occasionally, $3=$ often, $4=$ very often, $5=$ don't know).

The score was calculated by summing all the points of each section. The ECOHIS score was calculated by 
adding the scores of the two sections of the questionnaire.

Questionnaires with two or more unanswered items from the child section, or with one or more unanswered items from the family section, were excluded from the analysis.

\section{Statistical analysis}

The statistical analysis was performed using SPSS version 16 (Statistical Package for Social Sciences, IBM, Chicago, Illinois, USA) software. Chi-square test was done to compare the study population variable factors. Statistically significant differences were evaluated with significance set at $\mathrm{p}<0.05$.

\section{Results}

546 children and their parents have participated in our study. 300 (54.9\%) of them were male. 238 children $(43.6 \%)$ were aged between 4 and 5 years, and 308 (56.4\%) were in the range of 5 to 6 years.

Among the study population, the ECC had a prevalence of $74.2 \%$, and the severe form had a prevalence of

Table 1. Descriptive statistics

\begin{tabular}{|l|c|c|}
\hline Variables & $\mathbf{n}$ & \% \\
\hline Presence of the ECC & 405 & 74.2 \\
\hline -With S-ECC & 258 & 47.3 \\
\hline -Without S-ECC & 147 & 26.9 \\
\hline Absence of the ECC & 141 & 25.8 \\
\hline
\end{tabular}

Abbreviations: ECC: Early childhood caries, S-ECC: The severe early childhood caries

Table 2. Sociodemographic factors and mother's education associated with the presence of the S-ECC

\begin{tabular}{|l|c|c|}
\hline Variables & $\mathbf{n}$ & \% \\
\hline Sex & & \\
\hline Male & 141 & $54.7 \%$ \\
\hline Female & 117 & $45.3 \%$ \\
\hline Socio-economic level & & \\
\hline Low & 80 & 31.0 \\
\hline Medium & 154 & 59.7 \\
\hline High & 24 & 9.3 \\
\hline Mother's education & & \\
\hline Illiterate & 69 & 26.7 \\
\hline Primary & 90 & 34.9 \\
\hline Secondary & 71 & 27.9 \\
\hline University & 28 & 10.9 \\
\hline
\end{tabular}

Abbreviations: S-ECC: The severe early childhood caries
47.3\% (Table 1). The mean DMFT score was 3.978 . $54.7 \%$ of children with S-ECC were male, and 59.7\% had medium socioeconomic status (SES) (Table 2). $34.9 \%$ of children's mothers have received primary education, $27.5 \%$ of them have received secondary education, $10.9 \%$ have reached university and $26.7 \%$ of the mothers were illiterate.

The dietary habits prevalence (night-time breastfeeding/bottle feeding, sugar consumption between meals, bread sucking or similar habits) as well as hygiene practices (toothbrushing, usage of fluoride toothpaste) is reported in Table 3.

The prevalence of children with S-ECC who are exposed to passive smoking was estimated to be $39.9 \%$, with a significant difference compared to the nonexposed group (Table 3 ).

The evaluation of the quality of life, based on the parents' responses to the ECOHIS, showed that 59.3\% of children with ECC have experienced tooth pain at least one time. $41.5 \%$ of parents reported that their chil-

Table 3. Prevalence of the S-ECC according to dietary habits, oral hygiene practice and presence or no of the passive smoking

\begin{tabular}{|c|c|c|}
\hline Variables & $\mathbf{n}$ & $\%$ \\
\hline \multicolumn{3}{|c|}{ Night-time breast feeding } \\
\hline Yes & 181 & 70.2 \\
\hline No & 77 & 29.8 \\
\hline \multicolumn{3}{|c|}{ Night-time bottle feeding } \\
\hline Yes & 103 & 39.9 \\
\hline No & 155 & 60.1 \\
\hline \multicolumn{3}{|c|}{ Sugar consumption between meals } \\
\hline Yes & 224 & 86.8 \\
\hline No & 34 & 13.2 \\
\hline \multicolumn{3}{|c|}{ Sucking bread or similar habits } \\
\hline Yes & 89 & 34.5 \\
\hline No & 169 & 65.5 \\
\hline \multicolumn{3}{|c|}{ Frequency of child's brushing } \\
\hline Yes, after each meal & 9 & 3.5 \\
\hline Sometimes & 146 & 56.6 \\
\hline No & 103 & 39.9 \\
\hline \multicolumn{3}{|c|}{ Use of fluoride toothpaste } \\
\hline Yes & 79 & 51.0 \\
\hline No & 18 & 11.6 \\
\hline Don't Know & 58 & 37.4 \\
\hline \multicolumn{3}{|l|}{ Passive smoking } \\
\hline Yes & 103 & 39.9 \\
\hline No & 155 & 60.1 \\
\hline
\end{tabular}

Abbreviations: S-ECC: The severe early childhood caries 
dren have encountered eating difficulty, and $41.3 \%$ found it difficult to have hot or cold drinks.

The sleeping difficulty was noted in $27.9 \%$ of children with S-ECC, while preschool absenteeism was recorded among $22.5 \%$ of them. Due to dental problems or treatments; $43.7 \%$ of the children have felt irritated or frustrated.

Examination of responses related to family function indicated that approximately $40 \%$ of the parents reported that they have felt guilt, $43.4 \%$ of them have been upset, and $10.6 \%$ answered that they have taken time off work due to their child's oral health problems. The financial impact of health care has been reported by $18.5 \%$ of the respondents.

Furthermore, the distribution of responses to each ECOHIS question, which shows the impact of ECC on parents and children's life quality, was reported in Table 4.

The comparison of the ECOHIS scores reported among both groups; children with and without S-ECC, showed that the S-ECC has a statistically significant impact on the quality of life of the children as well as their parents (Table 5).

\section{Discussion}

The prevalence of the ECC is relatively high in some countries such as Morocco, and its specific management remains a significant public health challenge.

Our study shows a relatively high prevalence of ECC (74.2\%) as well as its severe form (47.3\%). Our results remain similar to those found by Kowash et al [7] in the United Arab Emirates (74.1\%), and to those found by Wulaerhan et al [8] in China (74.2\%). In contrast, a low prevalence of ECC has been demonstrated in some countries such as Italy (19.0\%) [9] and the USA (3 to 6\%).[10,11]

The variability in the ECC's prevalence within the literature can be explained by the inequality of socioeconomic conditions that influence the access to health care institutions, additionally, the availability of sufficient human and financial resources required to improve the child's oral health status.[12]

Table 4. Distribution of the ECOHIS parents' responses

\begin{tabular}{|c|c|c|c|c|c|c|}
\hline & Never & Hardly ever & Occasionally & Often & Very often & Don't know \\
\hline & n (\%) & n (\%) & n (\%) & n (\%) & n (\%) & n (\%) \\
\hline \multicolumn{7}{|l|}{ Impact on the child } \\
\hline 1. Painful in the teeth & $164(40.5)$ & $47(11.6)$ & $136(33.6)$ & $45(11.1)$ & $12(3.0)$ & $1(0.2)$ \\
\hline 2. Drinking difficulty & $235(58.0)$ & 48 (11.69) & $93(23.0)$ & $21(5.2)$ & $5(1.2)$ & $3(0.7)$ \\
\hline 3. Eating difficulty & $263(58.3)$ & $38(9.4)$ & $94(23.2)$ & $29(7.2)$ & $7(1.7)$ & $1(0.2)$ \\
\hline 4. Pronouncing words difficulty & $321(79.3)$ & $24(6.0)$ & $41(10.1)$ & $14(3.4)$ & $5(1.2)$ & $0(0)$ \\
\hline 5. Scholar absenteeism & $314(77.5)$ & $44(10.9)$ & $45(11.1)$ & $2(0.5)$ & $0(0)$ & $0(0)$ \\
\hline 6. Sleep disorder & $219(72.1)$ & $41(10.1)$ & $60(14.8)$ & $9(2.3)$ & $3(9.1)$ & $0(0)$ \\
\hline 7. Irritability and frustration & $225(55.6)$ & $42(10.4)$ & $86(21.2)$ & $73(9.1)$ & $12(3.0)$ & $3(0.7)$ \\
\hline 8. Smiling difficulty & $324(80.0)$ & $22(5.4)$ & $28(7.0)$ & $19(4.6)$ & $6(1.5)$ & $6(1.5)$ \\
\hline 9. Speaking difficulty & $32(84.4)$ & $29(7.2)$ & $15(3.7)$ & $8(2.0)$ & $6(1.5)$ & $5(1.2)$ \\
\hline \multicolumn{7}{|l|}{ Impact on the family } \\
\hline 10. Perturbation and disruption & $225(55.6)$ & $19(4.6)$ & $76(18.8)$ & $53(13.0)$ & $28(7.0)$ & $4(1.0)$ \\
\hline 11. Guilty feeling & $237(58.5)$ & $16(4.0)$ & $67(16.5)$ & $47(11.6)$ & $32(7.9)$ & $6(1.5)$ \\
\hline 12. Taken time of work & $355(87.7)$ & $14(3.4)$ & $20(5.0)$ & $8(2.0)$ & $1(0.2)$ & $7(1.7)$ \\
\hline 13. Financial impact & $321(79.3)$ & $18(4.4)$ & $24(6.0)$ & $18(4.4)$ & $15(3.7)$ & $9(2.2)$ \\
\hline
\end{tabular}

Abbreviations: ECOHIS: Early childhood oral health impact scale

Table 5. The comparison of means scores of the ECOHIS between children with ECC and S-ECC

\begin{tabular}{|l|c|c|c|}
\hline ECOHIS & Without S-ECC & With S-ECC & p \\
\hline Section impact on child & $\mathbf{n = 2 8 8}$ & $\mathbf{n = 2 5 8}$ & $<0.1$ \\
\hline Section impact on family & $2.84(4.87)$ & $7.32(5.73)$ & $<0.1$ \\
\hline Total score & $1.16(2.62)$ & $3.97(3.92)$ & $<0.1$ \\
\hline
\end{tabular}

Abbreviations: ECOHIS: Early childhood oral health impact scale, ECC: Early childhood caries, S-ECC: The severe early childhood caries 
Several factors have been identified as risk factors in our study, the same ones usually discussed within the literature such as socio-demographic factors, dietary habits (night-time breastfeeding/bottle feeding, sugar consumption between meals, bread sucking, or similar habits), oral hygiene practices (tooth brushing, usage of fluoride toothpaste) and passive smoking. [13,14]

To assess the effect of oral health problems on an individual's physical, mental, and social health, and well-being, requires specific tools. Many of those instruments have been recently developed for that purpose.

Pahel et al [15] have developed the "Early Childhood Oral Health Impact Scale"; ECOHIS in 2007, in order to evaluate the impact of oral health problems or treatments on the quality of life of preschool children (aged between 3 to 5 years) and their families.

The ECOHIS is a simple instrument which is intended to be used in the epidemiological surveys, in order to distinguish between children with or without dental disease experience. The ECOHIS has been translated, adapted, and validated within several studies confirming its effectiveness. In the present study, the Moroccan Arabic version; validated by Bourzgui et al [16], and the French version by Li et al [17] were both used.

The oral health-related quality of life (OHRQoL) among children involves special challenges; notably their significant dependence to non-verbal communication as well as their language immaturity, especially when it comes to expressing discomfort or pain. Consequently, it is difficult for parents to recognize their children's oral health problems and their impact.[18]

The findings of the present study confirm the hypothesis that ECC affects preschool children's and their families' quality of life negatively.

Experiencing tooth pain (59.3\%), irritation (43.7\%), eating difficulty (41.5\%), drinking difficulty (41.3\%), and sleeping trouble (27.9\%) were the most common repercussions reported by the children's parents, as found within several studies conducted in different developed and developing countries.

Despite the socio-economic and demographic status of the population, the impact of the ECC remains similar. However, the degree of these impacts varies between studies according to several factors, such as age, gender, and DMFT index of the child.[19-21]

The results of the present study are similar to those reported in Malaysia[22] but different from those found in Brazil, Hong Kong, and Turkey.[20,23,24] This disparity results may be due to the low socioeconomic status of the prefecture where the present study has been conducted, which is relatively similar to the situation in Malaysia.

In addition to the children's well-being, the ECC affects the quality of life of the family as well. Feeling upset (43.4\%), feeling guilty ( $40 \%$ ), the financial impact $(18.5 \%)$ and work absenteeism (10.6\%) are the most frequent problems encountered in the parents' section.

The negative feeling and guilt found in our study have been explored by Carvalho et al [25] The authors suggest that this feeling may be explained by the parents' oral health and dental prevention consciousness, with being enabled to put this awareness into practice at the same time.[25]

These main impacts are consistent with other studies but with varying percentages. The factors involved in this variation are the age of the sample, the severity of the ECC, as well as the age, the educational level, the oral history, and the economic status of the parents. In other studies, the main impacts of oral health within the family section were different from the present survey and were manifested more by the absenteeism and financial impact.[19-21]

The comparison between the impact of the ECC and the S-ECC on the children's and parents' quality of life has shown that the consequences are statistically significant with the S-ECC $(\mathrm{p}<0.00001)$. The same result was reported by Lee et al [6), Martins-Júnior et al [20], and Li et al [26].

\section{Conclusion}

The findings of the present study confirm that the ECC and its severe form have a negative impact on preschool children's and their family's quality of life.

These results highlight the need to implement effective strategies in order to improve children's oral health through the parents' and oral health caregivers' education, for better access to preventive dental care. It is also necessary to plan and organize specific programs focused on young children to reinforce the preventive message and provide practical advice to their parents, with the purpose of promoting children's oral health.

Conflict of Interest: None declared.

\section{References}

1. American academy of Pediatric Dentistry and American Academy of Pediatrics. Policy on early childhood caries (ECC): classifications, consequences and preventive strategies. Reference Manual (V40/ NO 6/ 18-19/P. 60-62). Latest Revision 2016

2. Anil S, Anand PS. Early childhood caries: prevalence, risk factors, and prevention. Front Pediatr 2017;5:157 Published 2017 Jul 18. doi:10.3389/fped.2017.00157 
3. Meyer F, Enax J. Early childhood caries: epidemiology, aetiology, and prevention. Int J Dent 2018;2018:1415873. Published 2018 May 22. doi:10.1155/2018/1415873

4. Nakayama Y, Mori M. Risk factors associated with early childhood caries in 18- to 23-month-old children in a Japanese city. J Natl Inst Public Health 2017;66(5):545-552

5. Hazar Bodrumlu E, Demiriz L, Toprak S. Relationship between severe early childhood caries and dental development. Eur J Paediatr Dent 2018;19(2):156-160 doi:10.23804/ ejpd.2018.19.02.11

6. Lee GH, McGrath C, Yiu CK, King NM. A comparison of a generic and oral health-specific measure in assessing the impact of early childhood caries on quality of life. Community Dent Oral Epidemiol 2010;38(4):333-339 doi:10.1111/j.16000528.2010.00543.x

7. Kowash MB, Alkhabuli JO, Dafaalla SA, Shah A, Khamis AH. Early childhood caries and associated risk factors among preschool children in Ras Al-Khaimah, United Arab Emirates. Eur Arch Paediatr Dent 2017;18(2):97-103 doi:10.1007/s40368-0170278-8

8. Wulaerhan J, Abudureyimu A, Bao XL, Zhao J. Risk determinants associated with early childhood caries in Uygur children: a preschool-based cross-sectional study. BMC Oral Health 2014;14:136 Published 2014 Nov 18. doi:10.1186/1472-6831-14-136

9. Ugolini A, Salamone S, Agostino P, Sardi E, Silvestrini-Biavati A. Trends in early childhood caries: an Italian perspective. Oral Health Prev Dent 2018;16(1):87-92 doi:10.3290/j.ohpd.a39816

10. Ripa LW. Nursing caries: a comprehensive review. Pediatr Dent 1988;10(4):268-282

11. Duperon DF. Early childhood caries: a continuing dilemma. J Calif Dent Assoc 1995;23(2):15-25

12. Chen KJ, Gao SS, Duangthip D, Lo ECM, Chu CH. Prevalence of early childhood caries among 5-year-old children: A systematic review. J Investig Clin Dent 2019;10(1):e12376 doi:10.1111/ jicd.12376

13. Vadiakas G. Case definition, aetiology and risk assessment of early childhood caries (ECC): a revisited review. Eur Arch Paediatr Dent 2008;9(3):114-125 doi:10.1007/BF03262622

14. Fan CC, Wang WH, Xu T, Zheng SG. Risk factors of early childhood caries (ECC) among children in Beijing - a prospective cohort study. BMC Oral Health 2019;19(1):34 Published 2019 Feb 18. doi:10.1186/s12903-019-0721-9

15. Pahel BT, Rozier RG, Slade GD. Parental perceptions of children's oral health: the Early Childhood Oral Health Impact Scale (ECOHIS). Health Qual Life Outcomes 2007;5:6 Published 2007 Jan 30. doi:10.1186/1477-7525-5-6
16. Bourzgui F, Saif S, Serhier Z, Diouny S, Othmani M. Adaptation and validation of the Moroccan Arabic Version of the Early Childhood Oral Health Impact Scale (ECOHIS). Int J Dent Res 2017;2(3):76-79

17. Li S, Veronneau J, Allison PJ. Validation of a French language version of the Early Childhood Oral Health Impact Scale (ECOHIS). Health Qual Life Outcomes 2008;6:9 Published 2008 Jan 22. doi:10.1186/1477-7525-6-9

18. Versloot J, Veerkamp JS, Hoogstraten J. Dental Discomfort Questionnaire: assessment of dental discomfort and/or pain in very young children. Community Dent Oral Epidemiol 2006;34(1):47-52 doi:10.1111/j.1600-0528.2006.00253.x

19. Naidu R, Nunn J, Donnelly-Swift E. Oral health-related quality of life and early childhood caries among preschool children in Trinidad. BMC Oral Health 2016;16(1):128 Published 2016 Dec 7. doi:10.1186/s12903-016-0324-7

20. Martins-Júnior PA, Vieira-Andrade RG, Corrêa-Faria P, Oliveira-Ferreira F, Marques LS, Ramos-Jorge ML. Impact of early childhood caries on the oral health-related quality of life of preschool children and their parents. Caries Res 2013;47(3):211218 doi: $10.1159 / 000345534$

21. Mansoori S, Mehta A, Ansari MI. Factors associated with Oral Health Related Quality of Life of children with severe -Early Childhood Caries. J Oral Biol Craniofac Res 2019;9(3):222-225 doi:10.1016/j.jobcr.2019.05.005

22. Hashim AN, Yusof ZY, Esa R. The Malay version of the Early Childhood Oral Health Impact Scale (Malay-ECOHIS)-assessing validity and reliability. Health Qual Life Outcomes 2015;13:190 Published 2015 Nov 25. doi:10.1186/s12955-0150386-2

23. Lee GH, McGrath C, Yiu CK, King NM. Translation and validation of a Chinese language version of the Early Childhood Oral Health Impact Scale (ECOHIS). Int J Paediatr Dent 2009;19(6):399-405 doi:10.1111/j.1365-263X.2009.01000.x

24. Peker K, Uysal Ö, Bermek G. Cross - cultural adaptation and preliminary validation of the Turkish version of the early childhood oral health impact scale among 5-6-year-old children. Health Qual Life Outcomes 2011;9:118 Published 2011 Dec 22. doi:10.1186/1477-7525-9-118

25. Carvalho TS, Abanto J, Mendes FM, Raggio DP, Bönecker M. Association between parental guilt and oral health problems in preschool children. Braz Oral Res 2012;26(6):557-563. doi:10.1590/s1806-83242012000600012

26. Li MY, Zhi QH, Zhou Y, Qiu RM, Lin HC. Impact of early childhood caries on oral health-related quality of life of preschool children. Eur J Paediatr Dent 2015;16(1):65-72 